\title{
Innovative approaches to neuraxial blockade in children: The introduction of epidural nerve root stimulation and ultrasound guidance for epidural catheter placement
}

\author{
Ban $\mathrm{CH}$ Tsui MSc MD FRCPC
}

\begin{abstract}
$\mathrm{BCH}$ Tsui. Innovative approaches to neuraxial blockade in children: The introduction of epidural nerve root stimulation and ultrasound guidance for epidural catheter placement. Pain Res Manage 2006;11(3):173-180.

Continuous epidural blockade remains the cornerstone of pediatric regional anesthesia. However, the risk of catastrophic trauma to the spinal cord when inserting direct thoracic and high lumbar epidural needles in anesthetized or heavily sedated pediatric patients is a concern. To reduce this risk, research has focused on low lumbar or caudal blocks (ie, avoiding the spinal cord) and threading catheters from distal puncture sites in a cephalad direction. However, with conventional epidural techniques, including loss-of-resistance for localization of the needle, optimal catheter tip placement is difficult to assess because considerable distances are required during threading. Novel approaches include electrical epidural stimulation for physiological confirmation and segmental localization of epidural catheters, and ultrasound guidance for assessing related neuroanatomy and real-time observation of the needle puncture and, potentially, catheter advancement. The present article provides a brief and focused review of these two advances, and outlines recent clinical experiences relevant to pediatric epidural anesthesia.
\end{abstract}

Key Words: Electrical epidural stimulation; Epidural anesthesia and analgesia; Pediatric; Review; Ultrasound
Des modes novateurs de bloc neuraxial chez les enfants : Présentation de la stimulation de la racine nerveuse péridurale et orientation échographique pour l'installation d'un cathéter péridural

L'anesthésie péridurale continue demeure la pierre angulaire de l'anesthésie régionale pédiatrique. Cependant, le risque de traumatisme catastrophique de la moelle épinière pendant l'insertion directe d'aiguilles dans les zones thoracique et lombaire haute chez les patients pédiatriques anesthésiés et ayant reçu de puissantes doses sédatives est inquiétant. Pour réduire ce risque, les recherches ont porté sur les anesthésies lombaires basses ou caudales (qui évitent la moelle épinière) et l'introduction d'un cathéter dans des foyers de perforation distale vers la tête. Cependant, avec les techniques péridurales traditionnelles, y compris la perte de résistance pour localiser l'aiguille, il est difficile d'évaluer l'installation optimale du bout du cathéter à cause de l'importante distance d'insertion. Les modes novateurs incluent la stimulation péridurale électrique pour la confirmation physiologique et la localisation segmentaire des cathéters périduraux et l'orientation échographique pour évaluer la neuroanatomie connexe et l'observation en temps réel de la perforation à l'aiguille et peut-être, la progression du cathéter. Le présent article fournit une brève analyse ciblée de ces deux progrès et souligne les récentes expériences cliniques de l'anesthésie péridurale en pédiatrie.
$\mathrm{P}$ recise identification of the needle and catheter in the epidural space is critical for effective and safe continuous epidural anesthesia. Particularly for pediatric patients, accurate segmental localization is important for avoiding local anesthetic toxicity and side effects through maximizing effect with minimal doses. Single-shot epidural blocks are associated with limited duration and segmental effects, and continuous epidural anesthesia has become popular to overcome these limitations (1). The standard for epidural needle localization technique has been loss-of-resistance (LOR) to saline or air, which has fairly accurate results for needle placement and remains popular (2). The challenges for accurately threading catheters within the small pediatric epidural space without malpositioning, while also confirming safe catheter tip placement at target nerve root levels, has spurred interest and research in guidance and localization techniques.

In the pediatric population, the introduction of both the stimulation catheter and ultrasound guidance for use in epidural anesthesia has received attention over the past several years. The technique of using electrical stimulation for accurate epidural catheter placement (also known as the Tsui test) has been described as "an important innovation" with predictions that this technique "should improve the safety of [epidural anesthesia]" (3). An editorial in Regional Anesthesia and Pain Medicine expanded on this with, "the Tsui test is easy to perfect and is probably one of the better determinants of catheter tip placement without any extra radiographic examinations...we are at the brink of a new era for improving the accurate placement of regional anesthesia catheters in anesthetized children" (4). The 'new era' described in this editorial suggests that epidural stimulation has the potential to resolve some of the key concerns in pediatric epidural anesthesia. Recently, in addition to the epidural stimulation test, epidural placement under ultrasound guidance has been introduced and shown to be beneficial in some pediatric studies (5-7). To overcome certain challenges associated with performing epidural anesthesia 
in children, including the anatomical space and requirement for deep sedation or anesthesia (with lack of sensory warnings from the patient), real-time visualization of the epidural space is promising. Ultrasound is particularly promising for the neonate and infant population (particularly for infants younger than six months of age) because their epidural spaces are more superficial and bony structures less developed than in adults (5). Nevertheless, one recent review article (2) summarized the current status of using ultrasound for epidural placement as "ultrasonography can be used to identify neuraxial structures during insertion and placement of epidural catheters in children," and "this technique is not meant to become routine practice for localization of the epidural space as it requires a rather complicated and expensive setting to guarantee sterility" (2).

The present article provides a brief and focused review on the new concepts of electrical stimulation and ultrasound to confirm and guide epidural catheter positioning, and outlines recent clinical experiences with these important advancements in pediatric epidural anesthesia.

\section{ISSUES IN PEDIATRIC EPIDURAL ANALGESIA}

Epidural anesthesia and analgesia have many beneficial effects in the pediatric patient population. Central neuraxial block not only improves postoperative pain relief, but also promotes earlier ambulation, allows rapid weaning from the ventilator, reduces time spent in the catabolic state and lowers circulating stress hormones (8). The key to effective epidural analgesia is accurate placement of the epidural catheter.

Precise placement of epidural catheters ensures that the dermatomes involved in the surgical procedure are selectively blocked, allowing minimal doses of local anesthetics to be used for maximal analgesia (9-11). Despite the many benefits of epidural analgesia, there is always an associated risk of catastrophic needle trauma to the spinal cord from direct thoracic and high lumbar epidural needle placement. The risk of such an event may be elevated in children because their epidural spaces are considerably smaller than those of adults (less than $2 \mathrm{~mm}$ in small babies) $(7,12)$, and epidural catheter placement is commonly performed under sedation or general anesthesia. Although reports of perioperative nerve injuries in pediatric patients receiving epidural anesthesia are rare, the fact that unconscious patients are unable to report paresthesias (the currently accepted warning sign of needle encroachment on the spinal cord) raises concern (13-18). Failure to recognize epidural needle or catheter placement in the intrathecal space followed by the injection of the usual epidural dose could also result in a total spinal block or serious neurological sequelae (19-22). The thoracic epidural space is particularly challenging in children because the spinal canal is narrower and catheter threading more challenging.

To circumvent the risks and technical challenges associated with thoracic or high lumbar needle punctures, threading epidural catheters from puncture sites at the low lumbar or caudal space (at the sacral notch) was introduced, although with variable success (23-26). Intuitively, shifting the puncture site caudally should be an attractive and feasible alternative to direct placement for procedures and major surgery involving dermatomes above T10 (27). However, the possibility of the catheter coiling and failing to advance to the appropriate level discouraged the widespread use of these approaches. Subsequently, it became well understood that the location of the catheter tip must be verified using an objective test such as radiography (28), ultrasound (29) or nerve stimulation (30). In addition, controlling catheter positioning is important for longer distances of insertion because there will be a greater danger of unwanted migration (2).

$\mathrm{X}$-ray imaging, in conjunction with a contrasting agent or radiopaque catheter, can precisely identify the tip of the catheter in specific anatomic locations. However, while fluoroscopy permits continuous real-time monitoring and adjustment of advancing catheters, it requires additional set-up, incurs increased expense and, more importantly, increases the patient's exposure to ionizing radiation (1). As a result, fluoroscopy is commonly avoided for routine use and is usually limited to difficult and/or special circumstances such as chronic epidural catheter placement. The electrical stimulation test, and to some extent ultrasound, has been shown to be more promising for catheter tip confirmation.

\section{Basic concepts}

\section{ELECTRICAL STIMULATION TEST}

The original epidural electrical stimulation test (Table 1) described by Tsui et al (30) confirms epidural catheter placement through stimulation of the spinal nerve roots (not the spinal cord) with low electrical current conducted through normal saline in the epidural space via an electrically conducting catheter. The stimulating catheter set-up requires the cathode lead of the nerve stimulator to be connected to the epidural catheter via an electrode adapter, while the anode lead is connected to an electrode on the patient's skin as the grounding site. To avoid misinterpretation of the stimulation response (eg, local muscle contraction may be confused with epidural stimulation), the ground electrode should be placed on the lower extremity for thoracic epidurals and on the upper extremity for lumbar epidurals. Because the typical epidural catheter is positioned $1 \mathrm{~cm}$ to $2 \mathrm{~cm}$ from the nerve roots, correct placement is indicated by a motor response elicited with a current between $1 \mathrm{~mA}$ and $10 \mathrm{~mA}$ (30-32). Any motor response observed with a significantly lower threshold current (less than $1 \mathrm{~mA}$ ) may indicate that a catheter is in the subarachnoid or subdural space, or is in close proximity to a nerve root $(33,34)$. In these rare cases, a motor response is elicited with a significantly lower threshold current because the stimulating catheter is either very close (less than $1 \mathrm{~cm}$ ) to the nerve roots or in direct contact with highly conductive cerebrospinal fluid.

In addition to confirming final catheter positioning, the epidural stimulation test can allow dynamic control over catheter placement, thereby assisting smooth placement and adjustments in the event of catheter migration, kinking or coiling. Elicited muscle twitches are observed from the lower limbs to the intercostal muscles as the catheter is threaded cranially. This minimizes the concerns of catheter coiling or kinking by immediately identifying these events at the time of insertion, allowing for any necessary adjustments $(35,36)$. The absence of muscle twitches or resistance to the advancing epidural catheter may be indicative of a curled or kinked catheter.

\section{Equipment}

There are two main requirements to effectively guide stimulating epidural catheters, particularly when long threading distances are required. The catheter set-up must be amendable to 
TABLE 1

Epidural electrical stimulation test (Tsui test)

\begin{tabular}{llc}
\hline Catheter location & Motor response & Current \\
\hline Subcutaneous & None & NA \\
Subdural & Bilateral (many segments) & $<1 \mathrm{~mA}$ \\
Subarachnoid & Unilateral or bilateral & $<1 \mathrm{~mA}$ \\
Epidural space & Unilateral & $<1 \mathrm{~mA}$ \\
$\begin{array}{c}\text { against nerve root } \\
\text { Nonintravascular }\end{array}$ & Unilateral or bilateral & $1 \mathrm{~mA}$ to $10 \mathrm{~mA}$ \\
& & (threshold current \\
& & increases after local \\
& & anesthetic is injected) \\
\multicolumn{1}{c}{ Intravascular } & Unilateral or bilateral & $1 \mathrm{~mA}$ to $10 \mathrm{~mA}$ (no \\
& & change in threshold \\
& & current after local \\
& & anesthetic is injected)
\end{tabular}

Confirmation of catheter placement in the epidural space is recieved once obtaining either a bi- or unilateral motor response, and when the threshold current is $1 \mathrm{~mA}$ to $10 \mathrm{~mA}$ initially and increases with injection of local anesthetic

both conducting electricity and preventing catheter malpositioning from coiling and kinking. Metal-containing catheters and conducting solutions are necessary for electrical conductivity, while adding reasonable rigidity through metal stylet reinforcement will assist correct positioning. Currently, neither commerically available peripheral stimulation catheters nor regular epidural catheters meet these requirements sufficiently, and modifications have been described which enable proper set-up. Thus, a special, commercially manufactured styletted catheter set-up (Epidural Positioning System using Tsui test with FlexTip Plus catheter, Arrow International Inc, USA) was previously developed (Figure 1) to achieve the requirements.

To conduct electrical pulses for eliciting appropriate motor responses, the peripheral stimulation catheter (eg, Stimulong Plus, Dyna Medical Corp, Canada; Pajunk GmbH Medical Technology, Germany) incorporates an internal fixed wire that extends beyond the distal lumen tip. Conversely, regular soft metal-containing epidural catheters (eg, FlexTip, Arrow International Inc, USA; Perifix FX, B Braun Medical Inc, USA; Spirol, Smith's Medical, USA), do not have their metal tip ending past the catheter and therefore require the injection of a conducting fluid into the epidural space to elicit a motor response. An ionic solution such as normal saline is used as the priming solution for the catheter. Despite this solution, the metal coil in the lumen (in contact with the conducting solution) is still required because the long length of the epidural catheter, or any air lock within its lumen, can increase the resistance for current flow and impede the electrical conduction through the solution. Based on the above requirements, the Arrow FlexTip Plus catheter was used in the initial clinical work (30-32). This catheter is an open-tip, single-orifice catheter constructed of a circumferential stainless steel coil with soft polyurethane. Regardless of manufacturer, previously mentioned metal-containing catheters are all suitable for performing the epidural stimulation test (37). Stimulating peripheral catheters have also been used successfully when performing the epidural stimulation test (38).

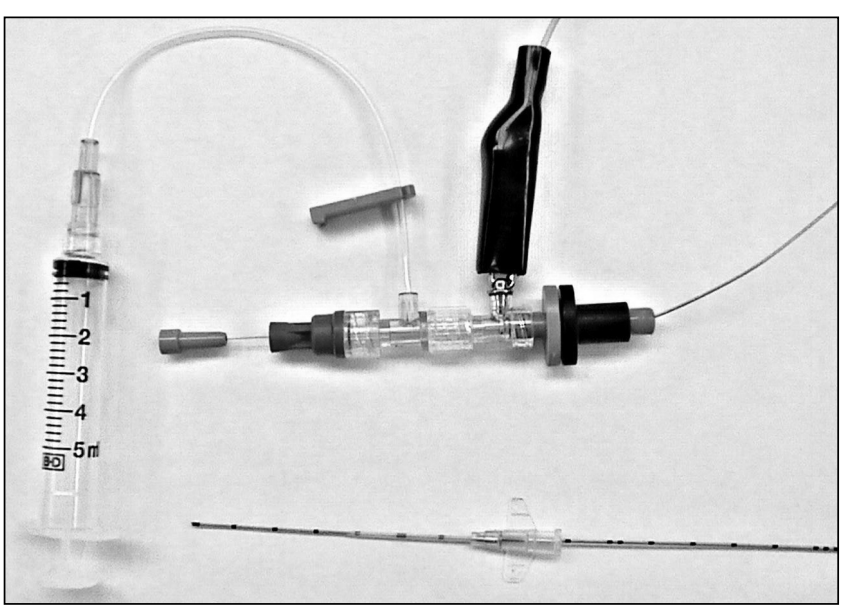

Figure 1) Equipment set-up (Epidural Positioning System using Tsui test, Arrow International Inc, USA). The set-up includes a commercially available 20-gauge epidural catheter with stylet and Johans electrocardiograph adapter assembly. The catheter assembly is passed through an 18-gauge intravenous catheter and the negative lead of the nerve stimulator is connected to the metal hub of the electrocardiograph adapter

While electrical conduction characteristics are paramount for indicating potential catheter migration or coiling, and confirming final catheter position, the regular metal-containing catheters are too soft for threading catheters over substantial distances, as with pediatric patients. To circumvent this, catheter reinforcement with a metal stylet to add some stiffness is desirable. While this stylet will increase ease of advancement within the epidural space, the electrical conduction characteristics need to be maintained; therefore, further modification to allow saline injection from the stylet-reinforced catheters is important.

Another function of this saline injection is to lubricate the epidural space to smooth the passage of the catheter. The fluid may reduce friction between the catheter and surrounding neural and connective tissue and, thus, limit encounters disrupting its advancement. Minor resistance to the passage of the catheter can be overcome by injecting normal saline through the advancing epidural catheter and/or simple flexion, or extension of the patient's vertebral column (36). Recently, the use of multiport catheters has been introduced and shows promise to maximize this lubrication effect (39). However, clinicians must remain vigilant because all techniques of epidural catheter placement have the potential for neurological injury. Therefore, under no circumstances should any force be used to advance the catheter.

Using the described design features, including a stylet and injection port system, epidural catheters have been successfully threaded from the caudal to thoracic spaces. In Canada, positive results have been demonstrated using a manufactured special styletted catheter set-up (Figure 1) (Arrow International Inc, USA) (39). However, in countries where those kits are not available, similar results can be obtained by 'in-house' modification of regular metal-containing catheters $(39,40)$. Despite this, widespread clinical use of epidural stimulation testing will obviously depend on further production and distribution of systems with the necessary features. 


\section{The safety of epidural electrical stimulation}

Electrical stimulation has been applied to neural structures for neurophysiological evaluation or pain control for decades (41). Chronic spinal cord stimulation has been shown to be an effective and safe means of controlling pain (41-44). The certainty of the safety of epidural stimulation is not completely known. However, it is anticipated that the risk of a brief intermittent electrical stimulation used in this test would be even lower than that of chronic epidural stimulation used in longterm pain management. Epidural stimulation uses milliamperage currents within the range used for patients with chronic pain disorders ( $4 \mathrm{~mA}$ to $30 \mathrm{~mA}$ ) (45) and for intraoperative monitoring during spinal surgery ( $2 \mathrm{~mA}$ to $40 \mathrm{~mA})(42,46-49)$. Although no known complications or patient discomfort have resulted from the epidural stimulation test, keeping the current below $15 \mathrm{~mA}$ and the stimulation time as brief (few minutes) as possible is recommended $(30-32,35,36)$. In particular, the current output must be carefully increased from zero and stopped once motor activity is visible to ensure that all motor responses, even those elicited with low current (less than $1 \mathrm{~mA}$ ), are detected. In addition, the nerve stimulator must be sensitive to allow a gradual increase in current output but should also be able to deliver currents to at least $10 \mathrm{~mA}$.

\section{Clinical applications}

Detecting intrathecal and intravascular placement: Aspiration should always be performed before local anesthetic injection. However, the inability to aspirate blood or cerebrospinal fluid is not an absolute indication that an epidural needle or catheter is not in the intrathecal or intravascular space. The use of electrical stimulation for epidural anesthesia may not only be useful to confirm epidural catheter placement, but the threshold current for motor response may also predict intrathecal placement $(33,38,50,51)$. When a catheter is situated properly within the epidural space, a current much greater than $1 \mathrm{~mA}$ should be required to elicit muscle twitches $(30,31,52)$. However, if any motor response is detected with a current less than $1 \mathrm{~mA}$, intrathecal placement should be suspected. Two recent clinical studies $(51,53)$ in pediatric patients demonstrated that the mean current necessary to elicit a motor response with insulated needles in the epidural space $(3.84 \pm 0.99 \mathrm{~mA}$ and $5.2 \pm 2.4 \mathrm{~mA}$, respectively) is much higher than that in the intrathecal space $(0.77 \pm 0.32 \mathrm{~mA}$ and $0.6 \pm 0.3 \mathrm{~mA}$, respectively). The advantage of this real-time stimulation test is that intrathecal placement can be ruled out before the administration of a potentially harmful test dose.

A previous obstetric study (31) has shown that repeated injections of local anesthetic into a properly placed epidural catheter results in impairment of nerve conduction, and requires a gradual increase in the amplitude of electrical current to produce a positive motor response to the stimulation test. Absence of this trend after repeated doses of local anesthetic suggests that the injected local anesthetic may be rapidly disappearing from the epidural space, as is the case with intravascular placement. Thus, intravascular catheter placement may be indicated by a positive motor response to appropriate stimulation currents $(1 \mathrm{~mA}$ to $10 \mathrm{~mA})$ that remain at or return to the baseline levels (ie, before any local anesthetic injection) despite the administration of local anesthetics. In addition to the obstetric study, intravascular catheter placement was detected using epidural stimulation in another case report (33). Caution is required when extrapolating this information because this application has never been examined in the pediatric population. An adrenaline test dose $(0.5 \mu \mathrm{g} / \mathrm{kg})$ should still be administered to identify inadvertent intravascular placement via specific electrocardiograph (ECG) changes (ie, greater than $25 \%$ increase in T wave or ST segment changes irrespective of chosen lead) $(54,55)$. Tobias (55) recommends the use of adrenaline test doses in children, because in all the studies he reviewed the specificity of the ECG changes was $100 \%$. Therefore, the ECG should be continuously monitored while injecting a local anesthetic and adrenaline test dose into the epidural space. However, when combined with the epidural stimulation test, the test dose can be given with confidence of a reduced risk of causing total spinal block.

\section{Guiding epidural placement:}

Caudal approach: Bosenberg et al (24) first described the technique of advancing catheters from the caudal space to the lumbar and thoracic region in infants and children. Subsequent studies have recommended that caudal catheter anesthesia should be limited to patients younger than one year of age because development of the lumbar curve during infancy can prevent easy threading of the catheter and may cause catheter kinking (28). However, with the introduction of new equipment and techniques, recent reports have demonstrated that caudal catheter advancement is even possible in older children using epidural stimulation $(4,36,40)$. The improved success rate in older children has been attributed to the use of a styletted catheter, which also allows the simultaneous injection of saline during advancement, and perhaps more importantly, the ability to monitor the advancing catheter tip by stimulation (36).

Before the introduction of the epidural stimulation test to confirm catheter placement at the author's institution, the analgesic success rate from pediatric epidural catheter placement was unacceptably low (68\%) (35). It is likely that improper catheter placement may have been a major contributing factor to this because during this time period confirmation techniques were thought to be impractical and as a result were rarely used $(25,27)$. However, following the introduction of the epidural stimulation test, the success rate of caudal analgesia increased dramatically to $84.9 \%$, while side effects remained at a minimum (36). By precisely placing epidural catheters close to the appropriate dermatomes with the help of epidural stimulation, the surgical incision may be selectively blocked with low doses of medication $(10,11,56)$. Consequently, surgical stress for the patient is reduced, along with any potential side effects. This is particularly important for neonates and infants, because they are prone to profound oxygen desaturation when distressed.

Effective analgesia without sedation, such as that provided by epidural anesthesia, can reduce the risk of prolonged postoperative ventilation. With properly sited epidurals, an infusion of $0.1 \%$ bupivacaine with $1 \mu \mathrm{g} / \mathrm{mL}$ of fentanyl is safe and effective in neonates and children (36). It is important to note that fentanyl is highly lipid soluble, with limited spread within the epidural space. This results in effective analgesia only when the epidural catheter tip is placed precisely at the incision level. From the author's experience, this advance to caudal catheter placement has obviated the need for ventilatory support in many children following major thoracic and abdominal procedures. Similar outcomes have also been reported in other centres using the same technique (40).

Increased risk of infection is a concern when using the caudal approach because the puncture site of the needle is in close 
proximity to the anus. However, clinical evidence to indicate a higher rate of infection with the caudal approach as opposed to a lumbar or thoracic approach has not been found despite higher bacterial colonization on caudal catheters $(36,57)$. Tunnelling caudal catheters or simply fixing the catheter with sterile occlusive dressing in an immediate cephalad direction has been recommended to reduce the risk of contamination by stool and urine $(36,58)$.

Lumbar approach: Lumbar epidural anesthesia is often used in lower extremity and urological surgery. Previous reports (23) of attempts to thread lumbar epidural catheters to the thoracic segment without epidural stimulation have described lack of success, because the flexible catheter tip is met with undue resistance at the lumbar curve. Despite favourable results using stimulation via a caudal approach, there have been only two recent case reports $(39,59)$ demonstrating the successful placement of a thoracic epidural catheter via the lumbar route with epidural stimulation guidance. Obviously, with so few cases of thoracic epidural catheter placement via lumbar approach using nerve stimulation, caution is required before making generalizations about the merits of this technique for this approach. Further research and study is warranted.

Thoracic approach: When using a direct thoracic approach, one is not limited by the ability to thread the epidural catheter because the selected site of entry corresponds directly with the dermatomes involved in the surgery. In this situation, epidural catheter stimulation does not seem to have significant benefit to LOR for improving accurate epidural catheter placement at specific nerve root levels (60). As previously mentioned, inadvertent intrathecal or intraneural needle placement may possibly be identified by patient reports of paresthesia or pain upon injection. Because pediatric patients are deeply sedated or under general anesthesia during placement of the neuraxial block, the electrical stimulation test may be an additional safety measure to alert the clinician of needle proximity to the intrathecal space, spinal cord or nerve root $(50,61)$. Thus, while it may not be advantageous for catheter placement verification with these blocks, electrical stimulation may still be useful.

\section{Limitations of epidural stimulation}

A major limitation of the epidural stimulation technique is that this test must be performed in the absence of a significant clinical neuromuscular blockade or local anesthetics in the epidural space. Although these obstacles can be overcome in many circumstances, alternative methods will be desirable in some cases. Tsui et al $(62,63)$ developed one such alternative monitoring technique using ECG monitoring. Essentially, the amplitude of the QRS complex matches the surface electrode amplitude as it passes the target level. A study (62) has shown that this technique can guide the catheter tip within two vertebral spaces of the targeted level. However, unlike the epidural stimulation test, the ECG technique cannot warn of a catheter placed in the subarachnoid or intravascular space. In addition, if the catheter is only threaded a short distance, the precise level of catheter may be difficult to predict because a significant difference in ECG signals would be difficult to detect. Recently, ultrasound imaging has been introduced and would be an alternative method for young children, although it is limited at this time for older children and adults (see next section).

Minor limitations of electrical stimulation are the need and cost for a 'specialized' stimulating catheter. However, the cost of the catheters may not be significant; clearly, the cost of ineffective analgesia or intrathecal/intervascular placement would be much higher. Because this epidural stimulation test can be performed in conscious patients without discomfort, satisfaction with the technique has been consistently high for both pediatric and adult patients in the author's experience.

\section{ULTRASOUND GUIDANCE FOR CAUDAL OR EPIDURAL CATHETER PLACEMENT}

\section{Basic concepts}

Ultrasound guidance during regional anesthesia is a rapidly growing interest for many anesthesiologists. The echotexture of the nerves and their surrounding structures is visualized through reflection of the ultrasound waves. In the periphery, nerves can be distinguished from surrounding soft and connective tissues by their shape, size and echogenicity. Nearby bony structures, being highly hyperechoic, and blood vessels, especially with Doppler assistance, are often used for verification of the nerve identity.

Ultrasound imaging can be an excellent tool to identify neuraxial structures in infants and children, particularly as their epidural spaces are superficial and the posterior elements of the spinal canal are less ossified than those of adults (5). The issue with extensive ossification in those much older than six months of age is that most of the ultrasound beam is reflected upon contact with the spinous processes and related bony structures. Visualization of the dura mater is thought best (6), although the ligamentum flavum, intrathecal space, spinal cord, nerve roots and fibres can all been seen adequately via a soft tissue window among the bony structures (7). Thus, continuous visualization of needle tip penetration and catheter advancement is often difficult. Indeed, precise catheter tip identity has been suggested to only be possible in infants younger than one year (64) or six months (29) of age, without the use of metal-coiled catheters (65). With ultrasound, the needle is often identified by the tissue it displaces and by an acoustic shadow beyond its tip (12). Catheter advancement is generally visualized indirectly by the surrogate markers of spread of injectate and movement of dura in the vicinity of its tip.

\section{Equipment}

Initial use of ultrasound in regional anesthesia by La Grange et al in 1978 (66) included Doppler ultrasound blood flow detection and vascular identification to estimate the position of nearby nerves. Today, technological developments have allowed ultrasound systems to deliver high-frequency sound waves (10 Hz or higher), offering the high resolution required for visualization of nerves and other tiny anatomical structures (12). While Doppler is still valuable to illuminate vascular landmarks when searching for nerves, it is no longer the primary approach in regional anesthesia. Although high-resolution images are possible in many circumstances, the depth of penetration varies inversely with the resolution, and there is often a tradeoff between depth and clarity of the image (5). This is especially relevant to viewing the epidural space, where deeper structures may be best viewed at lower frequencies with corresponding less clarity. As stated previously, children's epidural spaces are more superficial than those of adults, lending to somewhat higher resolution imaging (5 MHz to $10 \mathrm{MHz}$ ) (6).

Beyond delivery of the needed resolution, the portability and reduced cost of the machines make the technique viable in 
a clinical operating room setting. Available ultrasound systems are equipped with complex software to provide good visualization of tissue contrast at both superficial and deep levels, as well as allow image and data file storage (5). Several companies manufacture portable machines, including Sonosite Inc (USA), Toshiba (USA) and General Electric (USA).

\section{Clinical applications}

Potential advantages of using ultrasound compared with conventional techniques in regional anesthesia relate to the direct visualization of nerves, related anatomical structures and local anesthetic spread. This visualization may facilitate direction, for realignment of the needles for optimal local anesthetic spread; avoidance of intraneural and intravascular injections; reduction in dose of local anesthetic; faster sensory onset time; and longer duration and quality of blocks (5). Beyond puncture practices and application of medication, ultrasound may provide the anesthesiologist with a clear picture of the anatomical situation before administering the the block (67). Ultrasound has been proven beneficial during peripheral nerve blocks in adults and children, with advantages over nerve stimulation $(68,69)$ and landmark-based techniques $(70-72)$. Despite these benefits, evidence that ultrasound is widely acceptable and useful for central neuraxial block in children is still limited. A few studies have focused on the visibility of the needle and catheter, because the spinal canal is typically difficult to visualize sonographically (particularly in adults). Few others have studied the clinical efficacy of such use.

Chawathe et al (29) recently reported that, due to calcification of the posterior vertebral bodies in older children, ultrasound imaging is only reliable when used to image epidural catheters in children younger than six months of age. This imaging was performed after the block procedure rather than during insertion. Another study (64) concluded that one month of age was the threshold for clear catheter tip visibility, although only three children were studied (one, eight and 10 months of age). These studies used catheters without much echogenic property; the use of metal-coiled catheters, which appear bright with striated features, may circumvent this deficiency (65).

Measurements of the relationship between reference structures is a primary benefit of ultrasound; for example, the distance between the skin and epidural space can be measured before the epidural procedure, and the length of needle penetration when using the LOR technique can be estimated. Rapp et al (7) studied ultrasound-guided lumbar epidural catheter placement in 23 children and found a good correlation $(r=0.88)$ of ultrasound-measured depth of the epidural space with that from LOR (7). These authors reported fairly good visualization of the catheters, although only during insertion and therefore without ability to reassess the position postprocedure.

Comparing catheter placement using ultrasound guidance with that of LOR, Willschke et al (6) concluded that ultrasound, through visualizing the local anesthetic spread and neuraxial structures, speeded execution and reduced bone contacts during lumbar and thoracic epidural catheter placement in 64 children. Whether these primary outcome measures are appropriate or substantial enough to promote ultrasound guidance during pediatric epidural procedures is somewhat questionable. During LOR attainment, bone contact is often sought to confirm that the needle is 'walked off' the bone and hence, judging ultrasound as superior with reduced contact is perhaps misleading. The fact that these authors still found $17 \%$ bone contacts can also indicate poor visualization, because clear imaging should reduce this significantly. The bone was obviously misinterpreted as soft tissue; this highlights the fact that visualization of needle tips and tissue under ultrasound guidance is subject to significant operator interpretation. In addition, the authors did not include ultrasound start-up and preparation time with their calculation of swiftness, and the catheters were only threaded $2 \mathrm{~cm}$ to $3 \mathrm{~cm}$. Despite these, there was good ability to measure the skin-toepidural space and epidural diameter.

It is likely that many more reports of studies will be published in the near future to help assess the merit of ultrasound for pediatric neuraxial techniques. Likely, the main benefits will be preprocedure estimation of the epidural depth and diameter, as well as diagnosing variations in difficult conditions, such as scoliosis. Dynamic imaging and adjustment of catheters during threading may be helpful, especially with metalcoiled catheters. Visualizing the spread of local anesthetic should help reduce the dose of local anesthetic needed for maximum therapeutic effect. Improving safety and quality of blocks is still largely unknown at this time. Clearly, a cost-benefit analysis needs to be performed at each institution until more is known.

\section{Limitations of ultrasound}

Ultrasound imaging for regional anesthesia takes considerable time and effort to learn. Attempts to reduce the long learning curve may be effective to promote this technology throughout the anesthesiology community. Methods to best align the transducer with the block needle, to optimally view the needle tip and shaft, are continually sought (73). An important concern with continuous nerve blockade is the requirement for an assistant to hold the ultrasound probe during catheter advancement, making resource allocation an obvious consideration. The expense for the equipment, primary and additional practitioner training, as well as specific supplies and environment required for ultrasound (strict sterility is essential), may limit the benefit (2). These resources would, in the event of increased efficacy and safety, be justified.

Whether ultrasound guidance during epidural anesthesia improves safety, especially over that of epidural electrical stimulation, has yet to be determined. Understandably, it is hard to assess safety in situations of very rare incidence of harm. Regardless, the ability of electrical stimulation to confirm entrance to the epidural space and warn of intrathecal placement, both without a considerable learning curve, may promote this technique over that of ultrasound - at least with current technology and knowledge. However, with rapidly advancing technology, the image quality and capabilities of ultrasound will certainly improve and shorten the learning curve, making ultrasound more favourable. Nevertheless, time and study will tell.

\section{SUMMARY}

Epidural anesthesia can provide safe and effective analgesia in children. However, one must consider which epidural approach will be superior and which confirmation technique, if needed, will assist optimal catheter placement. Regional anesthesia techniques are intended for analgesia, rather than anesthesia, and very few adverse events should therefore ensue 
(2). Major complications from epidural anesthesia are rare if proper technique and precaution is exercised. Perhaps now, with the introduction of the stimulation catheter and portable ultrasound machines, anesthesiologists may have reliable tools not only to confirm catheter placement in the epidural space, but also to accurately determine where the catheter tip is in the central neuraxis. Apart from improving efficacy and safety, these techniques will also be valuable for training purposes (1). Although there has been a great deal of progress in the development of epidural techniques, there is still no evidence that direct thoracic epidural placement can be performed without risk. Thus, the risks and benefits of epidural blockade must be considered on an individual basis (74).

ACKNOWLEDGEMENTS: Supported in part by a Clinical Investigatorship Award, Alberta Heritage Foundation for Medical Research, Alberta. The author had a previous patent license agreement (US patent \#6190370) with Arrow International Inc (USA) for the epidural kit described in the present article.

\section{REFERENCES}

1. Tsui BC, Berde CB. Caudal analgesia and anesthesia techniques in children. Curr Opin Anaesthesiol 2005;18:283-8.

2. Dalens B. Some controversies in paediatric regional anaesthesia. Curr Opin Anaesthesiol 2006;19:301-8.

3. Desparmet JF. Epidural anesthesia in infants. Can J Anaesth 1999;46:1105-9.

4. Suresh S. Thoracic epidural catheter placement in children: Are we there yet? Reg Anesth Pain Med 2004;29:83-5.

5. Marhofer P, Greher M, Kapral S. Ultrasound guidance in regional anesthesia. Br J Anaesth 2005;94:7-17.

6. Willschke H, Marhofer P, Bosenberg A, et al. Epidural catheter placement in children: Comparing a novel approach using ultrasound guidance and a standard loss-of-resistance technique. Br J Anaesth 2006;97:200-7.

7. Rapp HJ, Folger A, Grau T. Ultrasound-guided epidural catheter insertion in children. Anesth Analg 2005;101:333-9.

8. Peutrell JM, Lonnqvist PA. Neuraxial blocks for anaesthesia and analgesia in children. Curr Opin Anaesthesiol 2003;16:461-70.

9. Berde CB. Convulsions associated with pediatric regional anesthesia. Anesth Analg 1992;75:164-6.

10. Larsson BA, Lonnqvist PA, Olsson GL. Plasma concentrations of bupivacaine in neonates after continuous epidural infusion. Anesth Analg 1997;84:501-5.

11. Luz G, Innerhofer P, Bachmann B, Frischhut B, Menardi G, Benzer A. Bupivacaine plasma concentrations during continuous epidural anesthesia in infants and children. Anesth Analg 1996;82:231-4.

12. Marhofer P, Willschke H, Kettner S. Imaging techniques for regional nerve blockade and vascular cannulation in children. Curr Opin Anaesthesiol 2006;19:293-300.

13. Broadman LM. Where should advocacy for pediatric patients end and concerns for patient safety begin? Reg Anesth 1997;22:205-8.

14. Bromage PR, Benumof JL. Paraplegia following intracord injection during attempted epidural anesthesia under general anesthesia. Reg Anesth Pain Med 1998;23:104-7.

15. Fischer HB. Regional anaesthesia - Before or after general anaesthesia? Anaesthesia 1998;53:727-9.

16. Fischer HB. Performing epidural insertion under general anaesthesia. Anaesthesia 2000;55:288-9.

17. Krane EJ, Dalens BJ, Murat I, Murrell D. The safety of epidurals placed during general anesthesia. Reg Anesth Pain Med 1998;23:433-8.

18. Rose JB. Spinal cord injury in a child after single-shot epidural anesthesia. Anesth Analg 2003;96:3-6.

19. Kasai T, Yaegashi K, Hirose M, Tanaka Y. Spinal cord injury in a child caused by an accidental dural puncture with a single-shot thoracic epidural needle. Anesth Analg 2003;96:65-7.

20. Palkar NV, Boudreaux RC, Mankad AV. Accidental total spinal block: A complication of an epidural test dose. Can J Anaesth 1992;39:1058-60.
21. Richardson MG, Lee AC, Wissler RN. High spinal anesthesia after epidural test dose administration in five obstetric patients. Reg Anesth 1996;21:119-23

22. Steffek M, Owczuk R, Szlyk-Augustyn M, Lasinska-Kowara M, Wujtewicz M. Total spinal anaesthesia as a complication of local anaesthetic test-dose administration through an epidural catheter. Acta Anaesthesiol Scand 2004;48:1211-3.

23. Blanco D, Llamazares J, Rincon R, Ortiz M, Vidal F. Thoracic epidural anesthesia via the lumbar approach in infants and children. Anesthesiology 1996;84:1312-6.

24. Bosenburg AT, Bland BA, Schulte-Steinberg O, Downing JW. Thoracic epidural anesthesia via caudal route in infants. Anesthesiology 1988;69:256-9.

25. Gunter JB, Eng C. Thoracic epidural anesthesia via the caudal approach in children. Anesthesiology 1992;76:935-8.

26. Rasch DK, Webster DE, Pollard TG, Gurkowski MA. Lumbar and thoracic epidural analgesia via the caudal approach for postoperative pain relief in infants and children. Can J Anaesth 1990;37:359-62.

27. Seefelder C. The caudal catheter in neonates: Where are the restrictions? Curr Opin Anaesthesiol 2002;15:343-8.

28. Valairucha S, Seefelder C, Houck CS. Thoracic epidural catheters placed by the caudal route in infants: The importance of radiographic confirmation. Paediatr Anaesth 2002;12:424-8

29. Chawathe MS, Jones RM, Gildersleve CD, Harrison SK, Morris SJ, Eickmann C. Detection of epidural catheters with ultrasound in children. Paediatr Anaesth 2003;13:681-4.

30. Tsui BC, Gupta S, Finucane B. Confirmation of epidural catheter placement using nerve stimulation. Can J Anaesth $1998 ; 45: 640-4$

31. Tsui BC, Gupta S, Finucane B. Determination of epidural catheter placement using nerve stimulation in obstetric patients. Reg Anesth Pain Med 1999;24:17-23.

32. Tsui BC, Guenther C, Emery D, Finucane B. Determining epidural catheter location using nerve stimulation with radiological confirmation. Reg Anesth Pain Med 2000;25:306-9.

33. Tsui BC, Gupta S, Finucane B. Detection of subarachnoid and intravascular epidural catheter placement. Can J Anaesth 1999;46:675-8

34. Tsui BC, Gupta S, Emery D, Finucane B. Detection of subdural placement of epidural catheter using nerve stimulation. Can J Anaesth 2000;47:471-3.

35. Tsui BC, Seal R, Koller J, Entwistle L, Haugen R, Kearney R. Thoracic epidural analgesia via the caudal approach in pediatric patients undergoing fundoplication using nerve stimulation guidance. Anesth Analg 2001;93:1152-5.

36. Tsui BC, Wagner A, Cave D, Kearney R. Thoracic and lumbar epidural analgesia via the caudal approach using electrical stimulation guidance in pediatric patients: A review of 289 patients. Anesthesiology 2004;100:683-9.

37. Tsui BC, Sze CK. An in-vitro comparison of the electrical conducting properties of multiport versus single-port epidural catheters for the epidural stimulation test. Anesth Analg 2005;101:1528-30.

38. Lena P, Martin R. Subdural placement of an epidural catheter detected by nerve stimulation. Can J Anesth 2005;52:618-21.

39. Tsui BC, Usher A, Kulkarni PR, Scott SL. Thoracic epidural catheters via the caudal and lumbar approaches using styletted multiple port catheters in pediatric patients: A report of three cases. Acta Aaesthesiol Scand 2006;50:514-7.

40. Tamai H, Sawamura S, Kanamori Y, Takeda K, Chinzei M, Hanaoka K. Thoracic epidural catheter insertion using the caudal approach assisted with an electrical nerve stimulator in young children. Reg Anesth Pain Med 2004;29:92-5.

41. North RB, Kidd DH, Zahurak M, James CS, Long DM. Spinal cord stimulation for chronic, intractable pain: Experience over two decades. Neurosurgery 1993;32:384-94.

42. Hoppenstein R. Percutaneous implantation of chronic spinal cord electrodes for control of intractable pain: Preliminary report. Surg Neurol 1975;4:195-8.

43. Krainick JU, Thoden U, Riechert T. Spinal cord stimulation in post-amputation pain. Surg Neurol 1975;4:167-70.

44. Richardson RR, Nunez C, Siqueira EB. Histological reaction to percutaneous epidural neurostimulation: Initial and long-term results. Med ProgTechnol 1979;6:179-84. 
45. Sherwood AM. Biomedical engineering aspects of spinal cord stimulation. Appl Neurophysiol 1981;44:126-32.

46. Komanetsky RM, Padberg AM, Lenke LG, et al. Neurogenic motor evoked potentials: A prospective comparison of stimulation methods in spinal deformity surgery. J Spinal Disord 1998;11:21-8.

47. Nagle KJ, Emerson RG, Adams DC, et al. Intraoperative monitoring of motor evoked potentials: A review of 116 cases. Neurology 1996;47:999-1004.

48. Pereon Y, Bernard JM, Fayet G, Delecrin J, Passuti N, Guiheneuc P. Usefulness of neurogenic motor evoked potentials for spinal cord monitoring: Findings in 112 consecutive patients undergoing surgery for spinal deformity. Electroencephalogr Clin Neurophysiol 1998; 108:17-23.

49. Wilson-Holden TJ, Padberg AM, Parkinson JD, Bridwell KH, Lenke LG, Bassett GS. A prospective comparison of neurogenic mixed evoked potential stimulation methods: Utility of epidural elicitation during posterior spinal surgery. Spine 2000;25:2364-71.

50. Tsui BC, Wagner A, Finucane B. The threshold current in the intrathecal space to elicit motor response is lower and does not overlap that in the epidural space: a porcine model. Can J Anaesth 2004;51:690-5.

51. Tsui BC, Wagner AM, Cunningham K, Perry S, Desai S, Seal R. Threshold current of an insulated needle in the intrathecal space in pediatric patients. Anesth Analg 2005;100:662-5.

52. Tsui BC, Seal R, Entwistle L. Thoracic epidural analgesia via the caudal approach using nerve stimulation in an infant with CATCH22. Can J Anaesth 1999;46:1138-42.

53. Tsui BC, Wagner AM, Cunningham K, Perry S, Desai S, Seal R. Can continuous low current electrical stimulation distinguish insulated needle position in the epidural and intrathecal spaces in pediatric patients? Paediatr Anaesth 2005;15;959-63.

54. Bosenberg A. Pediatric regional anesthesia update. Paediatr Anaesth 2004;14:398-402.

55. Tobias JD. Caudal epidural block: A review of test dosing and recognition of systemic injection in children. Anesth Analg 2001;93:1156-61.

56. Berde C. Local anesthetics in infants and children: An update. Paediatr Anaesth 2004;14:387-93.

57. Kost-Byerly S, Tobin JR, Greenberg RS, Billett C, Zahurak M, Yaster M. Bacterial colonization and infection rate of continuous epidural catheters in children. Anesth Analg 1998;86:712-6.

58. Bubeck J, Boos K, Krause H, Thies KC. Subcutaneous tunneling of caudal catheters reduces the rate of bacterial colonization to that of lumbar epidural catheters. Anesth Analg 2004;99:689-93.

59. Tsui, B C, Entwistle L. Thoracic epidural analgesia via the lumbar approach using nerve stimulation in a pediatric patient with Down syndrome: A case report. Acta Anaesthesiol Scand 2005;49:712-4

60. Goobie SM, Montgomery CJ, Basu R, et al. Confirmation of direct epidural catheter placement using nerve stimulation in pediatric anesthesia. Anesth Analg 2003;97:984-8

61. Tsui BC, Wagner A, Cave D, Seal R. Threshold current for an insulated epidural needle in pediatric patients. Anesth Analg 2004;99:694-6

62. Tsui BC, Seal R, Koller J. Thoracic epidural catheter placement via the caudal approach in infants by using electrocardiographic guidance. Anesth Analg 2002;95:326-30.

63. Tsui BC. Thoracic epidural catheter placement in infants via the caudal approach under electrocardiographic guidance: Simplification of the original technique. Anesth Analg 2004;98:273.

64. Roberts SA, Galvez I. Ultrasound assessment of caudal catheter position in infants. Pediatr Anesth 2005;15:429-32.

65. Bell GT, Bolton P. Caudal catheters and ultrasound. Pediatr Anesth 2006;16:92-9.

66. La Grange P, Foster PA, Pretorius LK. Application of the Doppler ultrasound bloodflow detector in supraclavicular brachial plexus block. Br J Anaesth 1978;50:965-7.

67. Grau T. Ultrasound in the current practice of regional anaesthesia. Best Pract Res Clin Anaesthesiol 2005;19:175-200.

68. Williams R, Saha B. Best evidence topic report. Ultrasound placement of needle in three-in-one nerve block. Emerg Med J 2006;23:401-3

69. Liu FC, Liou JT, Tsai YF, et al. Efficacy of ultrasound-guided axillary brachial plexus block: A comparative study with nerve stimulatorguided method. Chang Gung Med J 2005;28:396-402.

70. Soeding PE, Sha S, Royse CE, Marks P, Hoy G, Royse AG. A randomized trial of ultrasound-guided brachial plexus anaesthesia in upper limb surgery. Anaesth Intensive Care 2005;33:719-25.

71. Willschke H, Marhofer P, Bosenberg A, et al. Ultrasonography for ilioinguinal/iliohypogastric nerve blocks in children. $\mathrm{Br} J$ Anaesth 2005;95:226-30.

72. Williams SR, Chouinard P, Arcand G, et al. Ultrasound guidance speeds execution and improves the quality of supraclavicular block. Anesth Analg 2003;97:1518-23.

73. Tsui BC, Twomey C, Finucane BT. Visualization of the brachial plexus in the supraclavicular region using curved ultrasound probe with a sterile transparent dressing. Reg Anesth Pain Med 2006;31:182-4

74. Johr M, Berger TM. Recent developments in paediatric regional anaesthesia. Curr Opin Anaesthesiol 2004;17:211-5. 


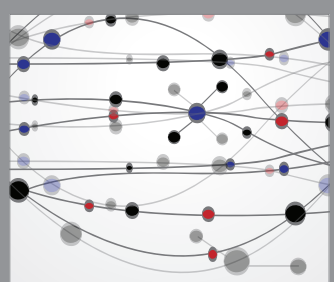

The Scientific World Journal
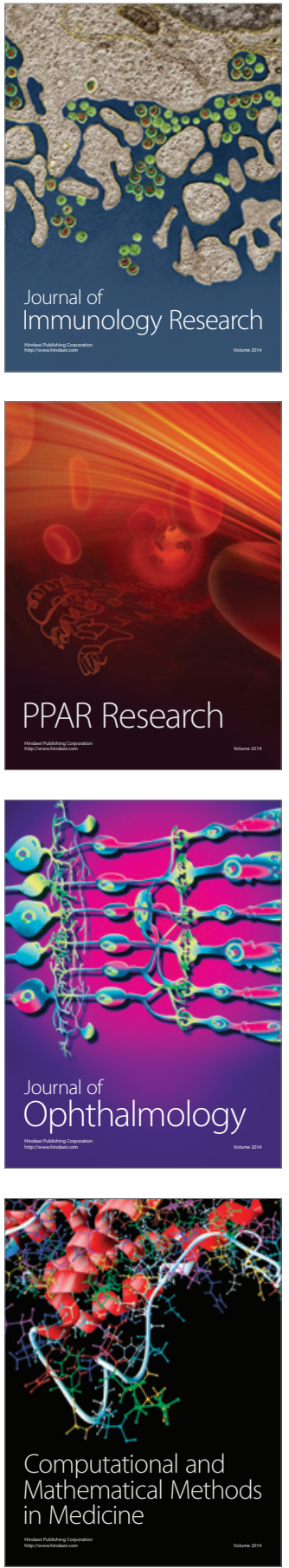

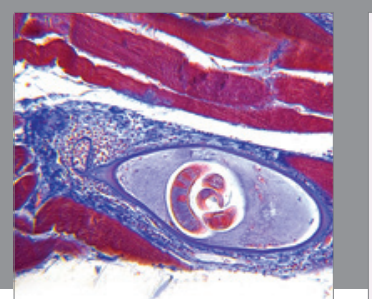

Gastroenterology Research and Practice

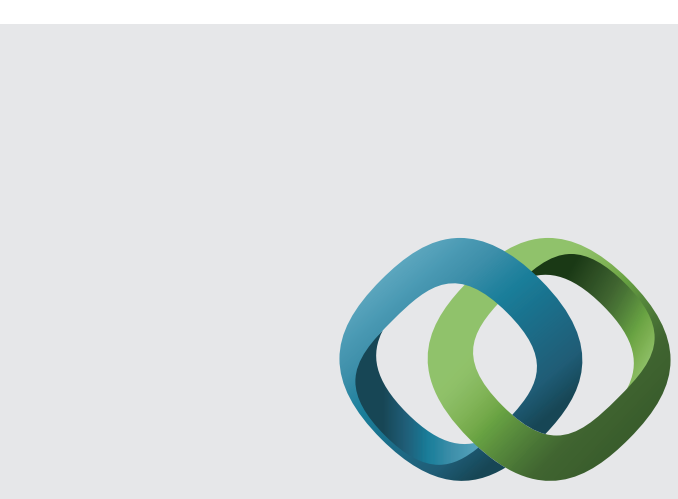

\section{Hindawi}

Submit your manuscripts at

http://www.hindawi.com
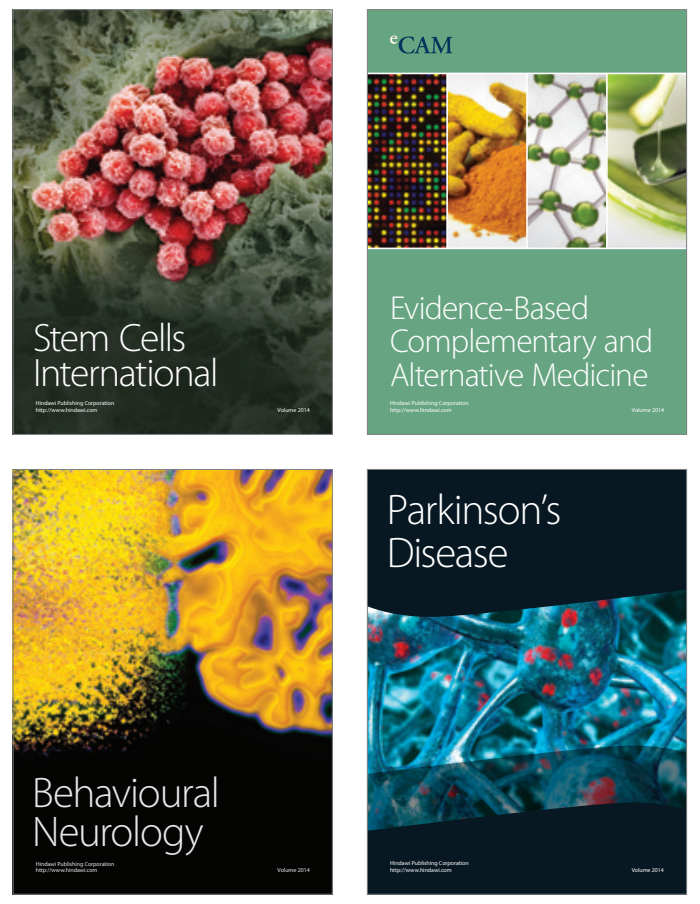
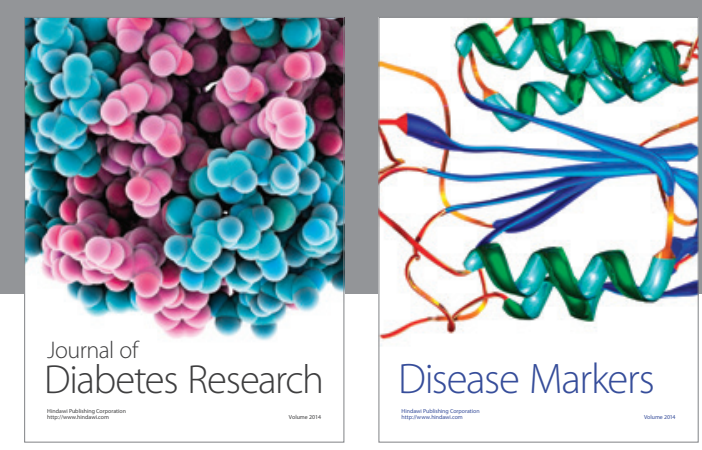

Disease Markers
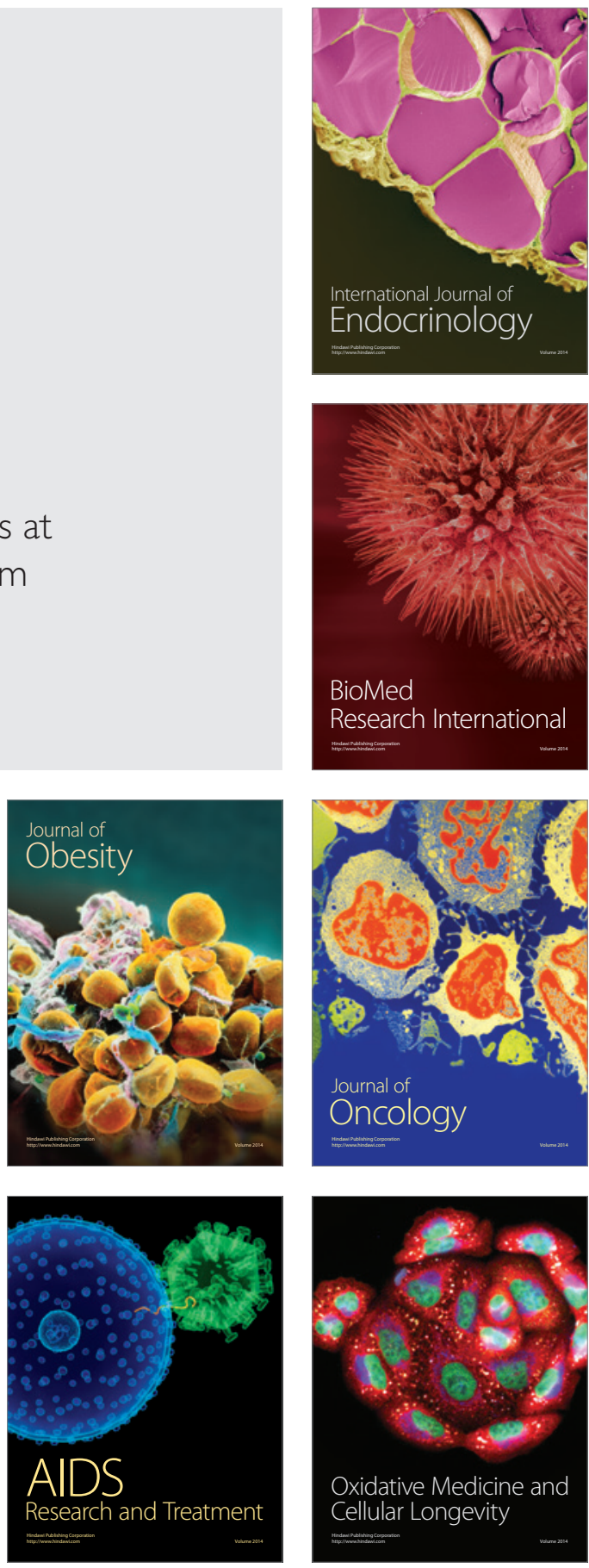